\section{Stress Analysis of Solar Electric Bus Chassis Using Finite Element Method}

\author{
Alief Wikarta”, Yolas Aditya Yudha \\ Department of Mechanical Engineering, Institut Teknologi Sepuluh Nopember, Surabaya 60111, Indonesia \\ Received: 3 January 2020, Revised: 5 March 2020, Accepted: 11 March 2020
}

\begin{abstract}
All of the electrical and mechanical components in the solar-electric bus certainly require a chassis. A chassis frame construction must be strong and light enough to bend when it receives loads. This article focuses on stress analysis using finite element method related to the solar-electric bus chassis, including the vertical load, longitudinal (acceleration and braking), and turning load. It began with a literature review and collecting the data of chassis dimensions and materials. It was then ended by getting the data simulation and evaluation of comparison results. From the simulation results for the chassis initial design, the highest Von-Misses stress happened for turning load, $182.45 \mathrm{MPa}$, and a safety factor of 1.4. While from simulation of the redesigned chassis, the Von-Mises stress reduced to $169.87 \mathrm{MPa}$ with a safety factor of 1.5. Furthermore, the vertical load conditions resulted in the lowest Von-Mises stress, which was $87.89 \mathrm{MPa}$ with a safety factor of 2.84 .
\end{abstract}

Keywords: finite element method, loading conditions, safety factor, stress analysis, solar electric bus chassis

\section{Introduction}

Nowadays, the use of electric vehicles is more common and effective because it has a simple construction. Electric vehicles are driven by electric motors using the electrical energy stored in the batteries. As with any other conventional vehicles, to put all electrical components in the electric solar bus, a chassis is needed. Besides being a place for attaching all components, the chassis also supports all the vehicle existing load. According to Sutantra [1], chassis is a vehicle component that functioned as a reinforcement that can withstand the vehicle load. Chassis is an essential part of a vehicle stability because all the components associated with strength are attached to the chassis.

To get an excellent chassis, it is necessary to analyze the chassis strength, whether it can withstand the load while staying within a safety limit when operated. Researchers have done several simulation studies about chassis strength, including light truck [2], formula student car [3], tubular space frame [4], race car [5], and actual bus structure [6]. All of the studies which are mentioned above focused on the conventional car with gasoline fuel. There are solar panels on the top of the body and a battery pack beneath the solar electric bus lower frame structures. Therefore, the chassis should accommodate all of those components within the safety limit.

This paper performs a chassis simulation using the finite element method to analyze the solar electric bus chassis strengths. The study focuses on the stress analysis and safety factor value related to the chassis. To produce a better chassis design, we also investigate two types of chassis: initial design and redesigned chassis.

\section{Method}

This study uses a simulation based on the finite element method. The electric bus chassis has 4 (four) types of loading: vertical load, acceleration load, braking load, and turning load. The parameters used to determine the effect of loading on the chassis strength are Von-Mises stress and safety factor. The chassis is safe if the simulation's result shows a safety factor above 1.5 for all loading conditions.

The vertical load comes from several sprung mass located in chassis structures, such as solar cell, battery pack, passenger, and electric power train (motor, gearbox, controller). Meanwhile, the acceleration and braking load (longitudinal) appears during acceleration and deceleration conditions. When it accelerates, the chassis will accept the following load: inertia load caused by the sprung and un-sprung masses ahead, vertical load, thrust load of the rear wheels, and reaction load on the support suspension.

Electric buses reach a distance of 100 meters in 8 seconds from a standstill. Thus the data was obtained from the acceleration calculation using Equation 1] [7]. In the braking process, the solar electric bus can decelerate the speed of $50 \mathrm{~km} / \mathrm{h}$ to $0 \mathrm{~km} / \mathrm{h}$ at a distance of 30 meters. So from these assumptions, deceleration was obtained from the calculation using Equation 2. Furthermore, when turning to the right, the solar electric bus can turn in a radius of 9 meters at a speed of $20 \mathrm{~km} / \mathrm{h}(5.56 \mathrm{~m} / \mathrm{s})$, then

*Corresponding author. Email: wikarta@me.its.ac.id 
the bus inertial forces can be calculated with the following Equation 3.

$$
\begin{gathered}
s=V_{o} t+\frac{1}{2} a t^{2} \\
V_{t}^{2}=V_{o}^{2}+2 a s \\
F_{\text {lateral }}=m_{\text {total }} \cdot K \cdot a_{\text {centrifugal }}
\end{gathered}
$$

where:

$$
\begin{array}{ll}
s & =\text { distance }(\mathrm{m}) \\
V_{o} & =\text { initial velocity }(\mathrm{m} / \mathrm{s})=0 \\
a & =\text { acceleration }\left(\mathrm{m} / \mathrm{s}^{2}\right) \\
t & =\text { time }(\mathrm{s}) \\
m & =\text { mass }(\mathrm{kg})
\end{array}
$$

Table 1 shows the boundary conditions for the simulation of the solar-electric bus chassis. In each loading condition, the boundary conditions are different according to the bus actual state when it operates. Meanwhile, the meshing process used tetrahedron elements with a total of 422,898 nodes and 223,887 elements that are shown in Figure 1 .

\section{Results and Discussion}

Chassis simulation using the finite element method resulted in total deformation and maximum bending stress. After knowing the maximum bending stress on the chassis, the chassis safety factor can be calculated as a measure of whether the chassis is safe or not. Figure 2 shows the simulation results in Von-Mises stress for all loading conditions. The vertical load condition produced the smallest maximum Von-Mises stress, $111.09 \mathrm{MPa}$, compared to other loading conditions. Meanwhile, the turning load resulted in the largest maximum Von-Mises stress, which was $182.45 \mathrm{MPa}$. For acceleration and braking conditions, the maximum Von-Mises stresses were 169.08 MPa and 174.75 MPa, respectively.

Table 1. Types of loading and boundary conditions

\begin{tabular}{|c|c|c|}
\hline No & Load analysis & Boundary conditions \\
\hline 1 & Vertical load & Fixed support both front and rear suspension \\
\hline 2 & Acceleration load & Fixed support both rear suspension \\
\hline 3 & Braking load & Fixed support both front suspension \\
\hline 4 & Turning load & Fixed support both left suspension \\
\hline
\end{tabular}

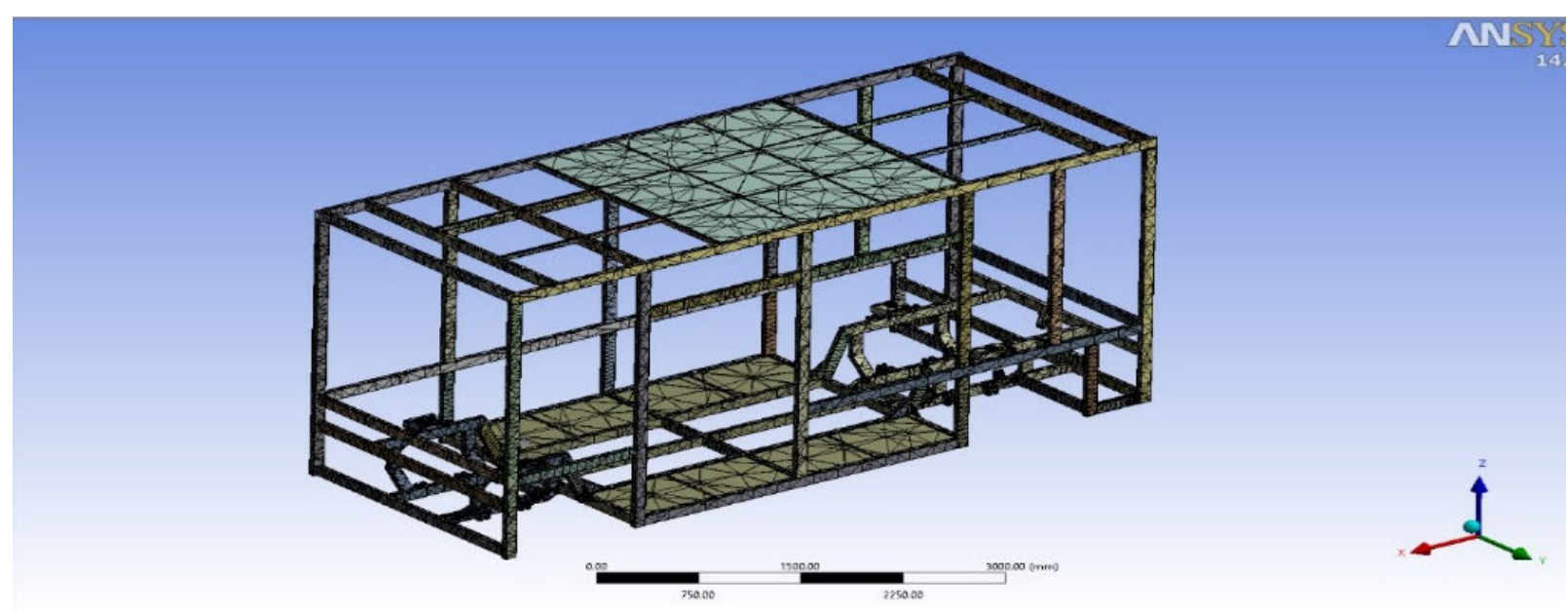

Figure 1. The meshing of the electric bus chassis 


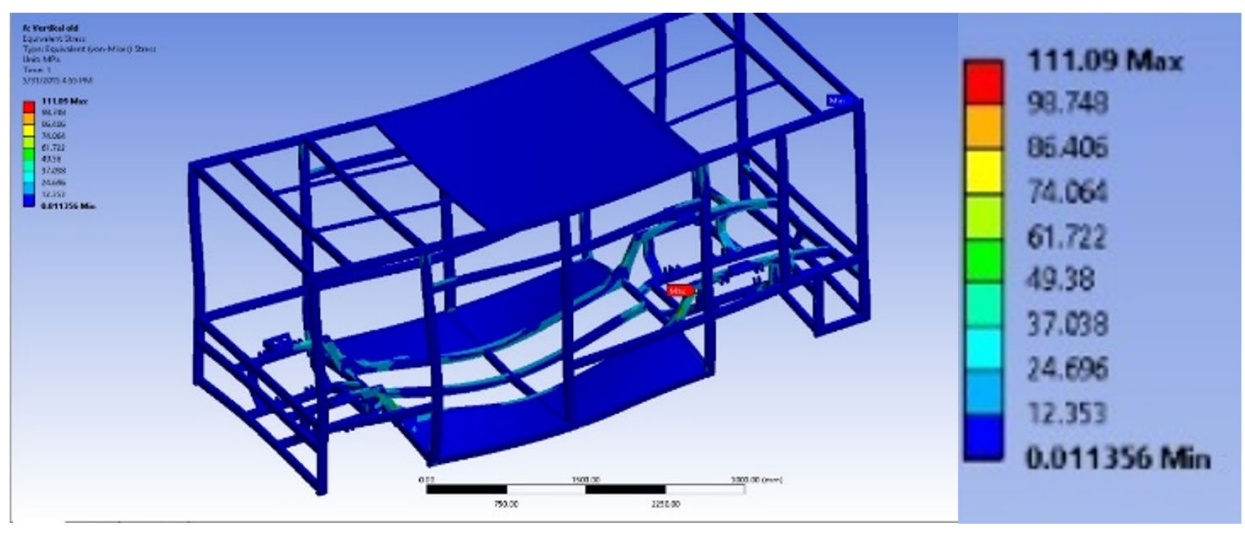

(a)

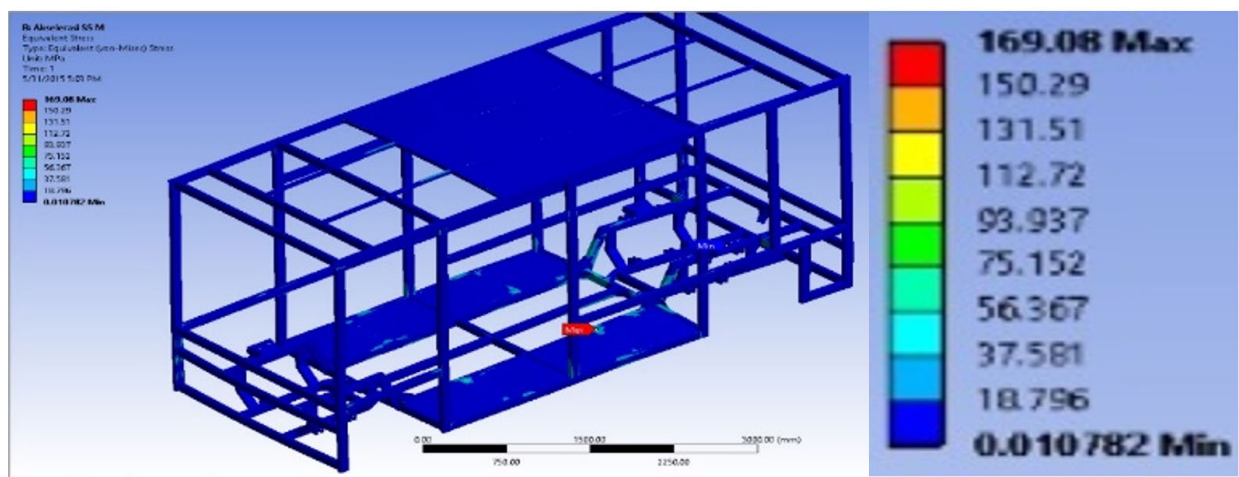

(b)

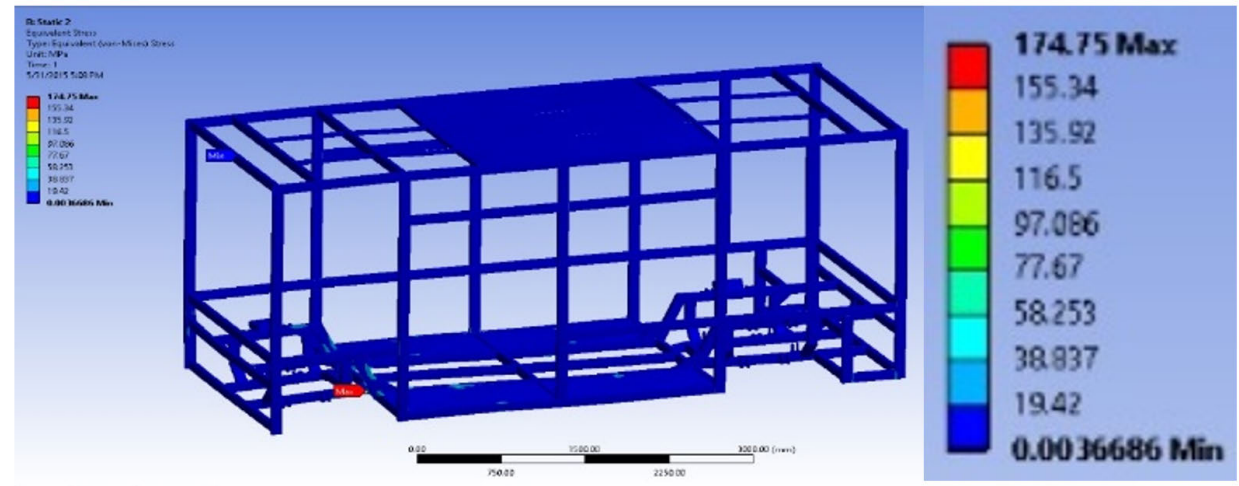

(c)
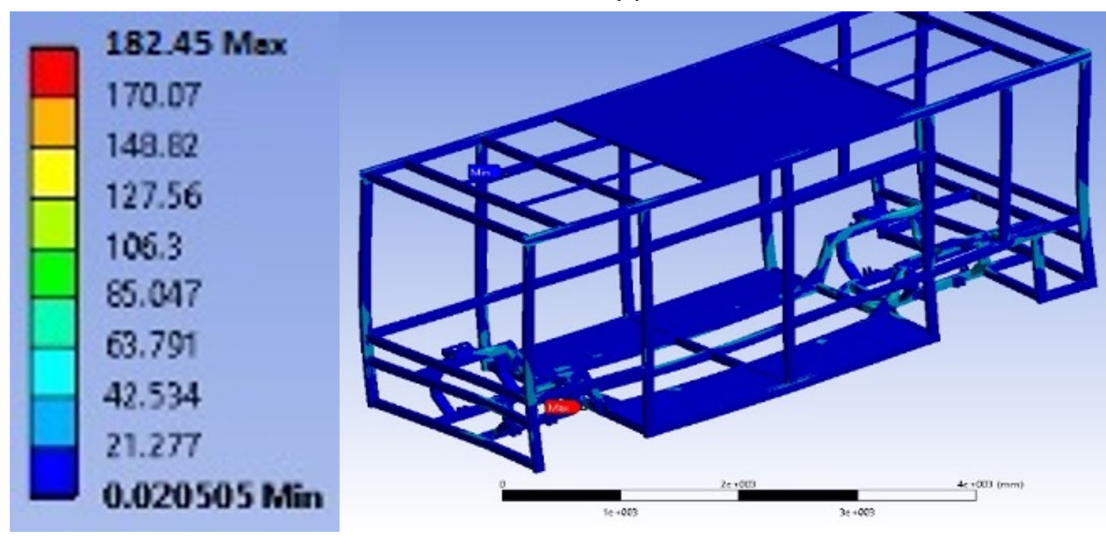

(d)

Figure 2. Von Mises Stress for (a) vertical Load, (b) acceleration, (c) braking, and (d) turning conditions 
Chassis is in a safe condition if it has a safety factor of at least 1.5. Table 2 shows the safety factor value of various loading conditions. For the braking and turning load conditions, the safety factor value was 1.4 . It indicated that the chassis was unsafe during braking and turning situations. For this reason, a redesign was needed to strengthen the chassis structure so that it is safe when exposed to braking and turning loads.

Figure 3 shows the chassis structure redesign instead of the initial design, where a diagonal bracing was added to the lower frame of the chassis. The addition of this diagonal bracing was expected to increase the chassis strength, especially during braking and turning conditions. Figure 4 compares the Von-Mises stress simulation results between the initial design and the redesigned chassis. The redesigned chassis provided a lower maximum Von-mises stress than the initial design for all loading conditions. In the braking and turning conditions, the maximum VonMises stress decreased to 161.21 MPa and 169.87 MPa, respectively. It shows that diagonal bracing on the underside of the chassis provides additional reinforcement.

Table 2. Maximum Von-Mises stress and safety factor for all loading conditions

\begin{tabular}{|c|c|c|c|}
\hline No & Loading Conditions & $\begin{array}{c}\text { Maximum } \\
\text { Von Mises stress (MPa) }\end{array}$ & Safety Factor \\
\hline 1 & Vertical & 111.09 & 2.3 \\
\hline 2 & Acceleration & 169.08 & 1.5 \\
\hline 3 & Braking & 174.75 & 1.4 \\
\hline 4 & Turn & 182.45 & 1.4 \\
\hline
\end{tabular}

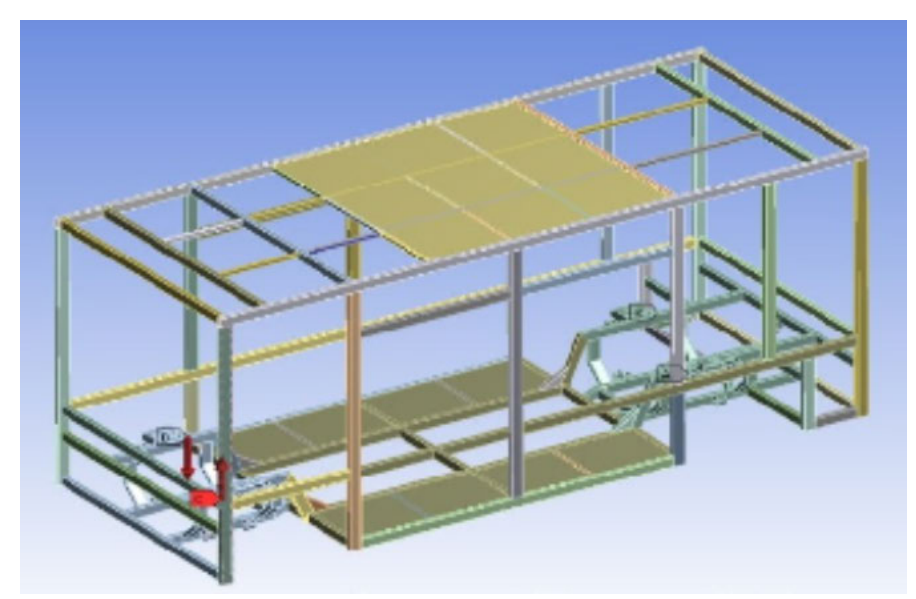

(a)

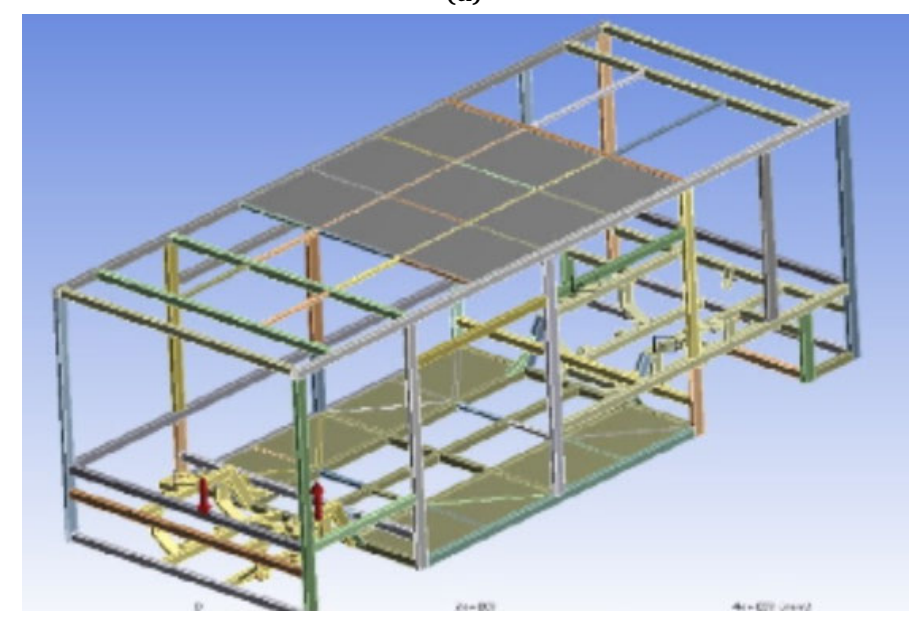

(b)

Figure 3. Chassis structure (a) initial design, (b) after the redesign 


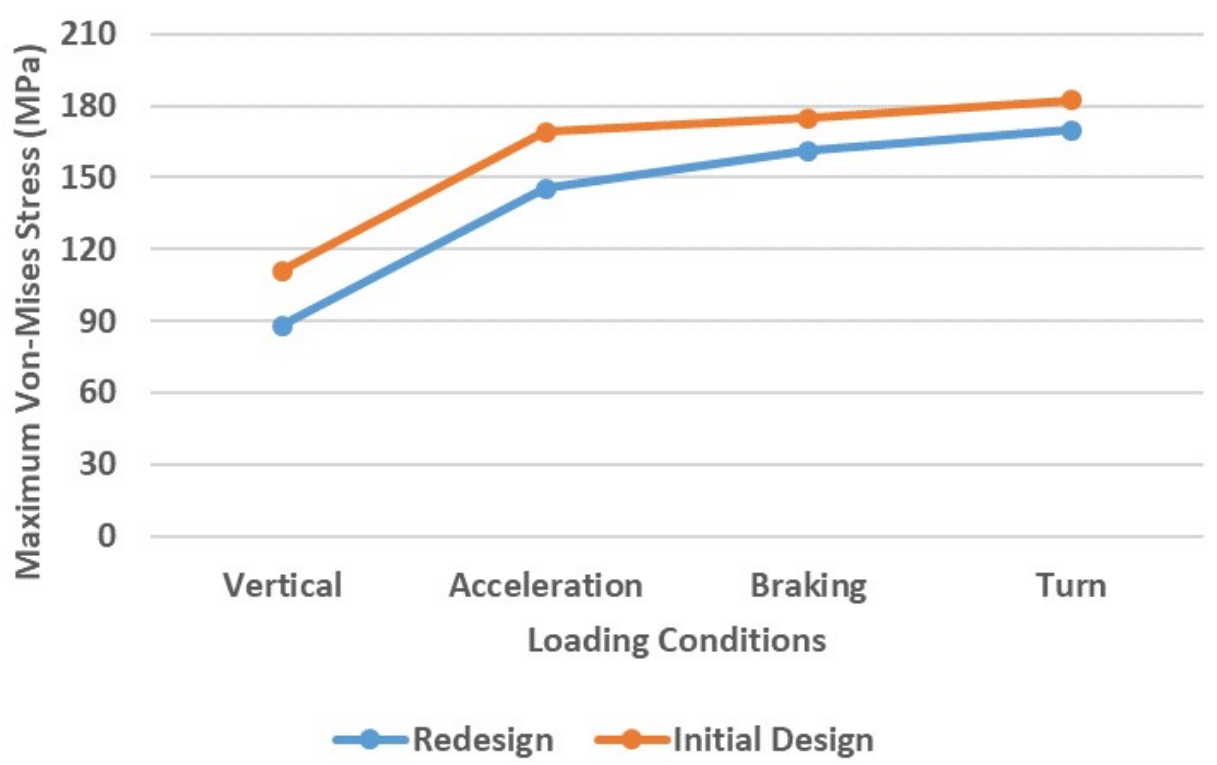

Figure 4. Comparison of maximum Von-Mises stress between initial design and redesigned chassis for all loading conditions

The safety factor calculation was then performed to determine the redesigned chassis structure safety, as shown in Figure 5. The safety factor value has increased in the redesigned chassis compared to the initial design for all loading conditions. Particularly for braking and turning loads, the safety factor value has increased from 1.4 to greater than 1.5. It shows that the redesigned chassis was in a safe condition when subjected to braking and turning loads. Therefore, the simulated redesigned chassis of the solar-electric bus with the finite element method was in a safe condition for all loading conditions.

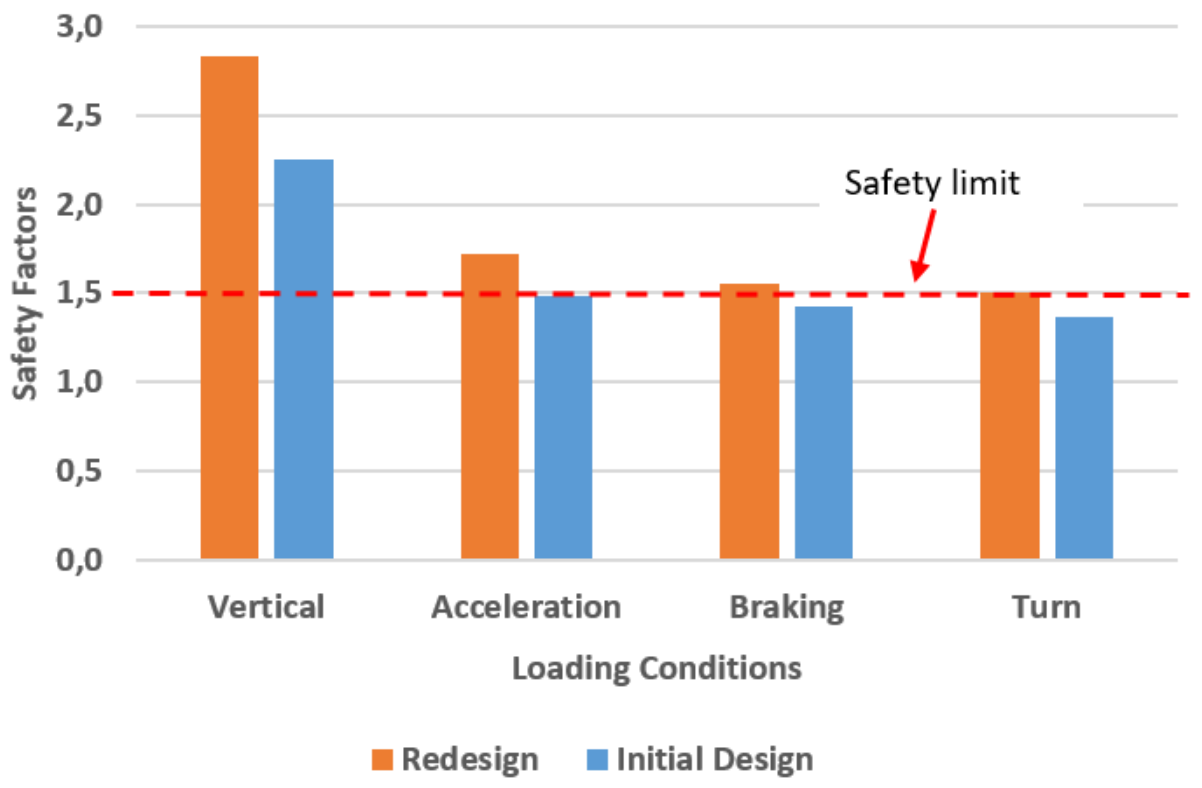

Figure 5. Comparison of safety factor between initial design and redesigned chassis for all loading conditions 


\section{Conclusions}

The stress analysis of solar-electric bus chassis has been done in this simulation study. All loading conditions have been analyzed, including vertical load, acceleration, braking, and turning load. For the chassis initial design, the highest Von-Misses stress happened for turning load which was $182.45 \mathrm{MPa}$ with a safety factor of 1.4. While from simulation of the redesigned chassis, the Von-Mises stress reduced to $169.87 \mathrm{MPa}$ with a safety factor of 1.5 . It means the redesigned chassis is safe when subjected to all loading conditions, including braking and turning loads.

\section{References}

[1] I. N. Sutantra, Teknologi Otomotif Teori dan Aplikasinya. Surabaya: Guna Widya, 2001.

[2] D. Y. Chen, L. M. Wang, C. Z. Wang, L. K. Yuan, T. Y. Zhang, and Z. Z. Zhang, "Finite element based improvement of a light truck design to optimize crashworthiness," Int.J Automot. Technol., vol. 16, no. 1, pp. 39-49.

[3] F. Adhim and A. Wikarta, Analisis Struktural Performa Chassis Sapuangin Speed 2013. Surabaya, 2014.

[4] V. N. B. P. Sodisetty, A. Pandey, D. B. Iyer, and N. Kumar, "Torsional stiffness analysis of a tubular spaceframe chassis," Tech. Rep., SAE Technical Paper, 2019.

[5] L. Hamilton, P. Joyce, C. Forero, and M. McDonald, "Production of a composite monocoque frame for a formula SAE racecar," Tech. Rep., SAE Technical Paper, 2013.

[6] A. Gauchia, V. Diaz, M. Boada, and B. Boada, "Torsional stiffness and weight optimization of a real bus structure," International Journal of Automotive Technology, vol. 11, no. 1, pp. 41-47, 2010.

[7] J. C. Brown, A. J. Robertson, and S. T. Serpento, Motor vehicle structures: Concepts and fundamentals. Butterworth-Heinemann, 2002. 